Ensaio sobre a colonialidade através da história da república democrática do congo: da necropolítica à transmodernidade. Revista Ensaios, vol. 14, jan-jun de 2019.

\title{
Ensaio sobre a colonialidade através da história da república democrática do congo: da necropolítica à transmodernidade.
}

\author{
Beatriz Castelo Branco Maciel ${ }^{1}$
}

Resumo: O presente trabalho pretende abordar temas como necropolítica, colonização, colonialidade e transmodernidade através da perspectiva histórica da República Democrática do Congo (RDC) e a Grande Guerra do Congo (1998-2003), exemplificando alguns dos reflexos da colonialidade na modernidade. O intuito desse ensaio é ilustrar as teorias de autores como Achille Mbembe, Aníbal Quijano, Aimé Césaire, Ramón Grosfoguel, Walter Mignolo e Júlio Roberto Pinto com os acontecimentos do país africano desde a colonização até a Grande Guerra, na virada do século XX para o século XXI.

Palavras-chave: República Democrática do Congo, colonização, colonialidade, necropolítica, transmodernidade, África

\section{Essay about coloniality throughout the history of democratic republic of congo:} from necropolitics to transmodernity

Abstract: The present essay aims to present definitions as necropolitics, colonization, coloniality and transmodernity throughout the perspective of the history of Democratic Republic of Congo (DRC) and the Great War of Africa (1998-2003) as examples of the impacts of coloniality in modernity. The intention of this work is to illustrate the theories of Achille Mbembe, Aníbal Quijano, Aimé Césaire, Ramón Grosfoguel, Walter Mignolo and Júlio Roberto Pinto thorugh the events in the african country since colonization until the Great War, at the turn from the XX to the XXI century.

Keywords: Democratic Republic of Congo, colonization, coloniality, necropolitics, transmodernity, Africa

\footnotetext{
${ }^{1}$ Universidade Federal Fluminense (UFF), Programa de Pós-graduação em Sociologia (PPGS), Niterói, RJ, Brasil.bmac.bea@gmail.com.
} 
Ensaio sobre a colonialidade através da história da república democrática do congo: da necropolítica à transmodernidade. Revista Ensaios, vol. 14, jan-jun de 2019.

Para compreender os movimentos diaspóricos do sul global na atualidade é preciso também compreender os mecanismos sócio-históricos que desencadearam esses processos. Para isso, é preciso nos remeter ao legado de um dos principais aspectos da modernidade: a colonização e, adiante, os resquícios desta (que aqui analisamos sob o nome de colonialidade) no mundo atual.

Minha pretensão com o presente artigo é associar as análises de Anibal Quijano, Maria Regina Petrus Tannuri, Achille Mbembe, Boaventura de Sousa Santos, Aimé Césaire, Ramón Grosfoguel, Walter Mignolo e Júlio Roberto Pinto ao contexto da República Democrática do Congo, desde sua colonização até os mais recentes episódios de guerra no país. Meu interesse pela RDC (República Democrática do Congo) se deu a partir do meu contato com congoleses na Cáritas Arquidiocesana do Rio de Janeiro e das histórias que pude ouvir durante meu tempo de trabalho de campo na instituição, entre agosto de 2017 e o presente momento.

As perspectivas étnico-raciais também se fazem presentes nesse artigo, uma vez que estão diretamente relacionadas aos processos de colonização, desestruturação de sociedades tradicionais, guerras, (des)acordos políticos e interesses estratégicos de exploração de matérias primas.

A importância de abordar a colonialidade na modernidade é também a de entender que vivemos processos que derivam necessariamente de um passado de colonização européia: de escravidão e trabalho forçado, de evangelização de povos nativos e de conflitos por território e matérias primas. As forças que se agitam no mundo atual têm conexão direta com um passado não tão distante assim, que ainda se reflete nas relações entre estados-nação e entre diferentes etnias. Nas palavras de Quijano, a colonialidade se mostrou mais duradoura e estável que o colonialismo, tornando-se um poder hegemônico (QUIJANO, 2005). Perceber, então, os conflitos atuais a partir dessa ótica é o esforço que tentarei fazer nas próximas páginas.

\section{A República Democrática do Congo}


Ensaio sobre a colonialidade através da história da república democrática do congo: da necropolítica à transmodernidade. Revista Ensaios, vol. 14, jan-jun de 2019.

A RDC foi "descoberta" pelo português Diogo Cão em 1482 e sua colonização durou quase 400 anos, terminando somente em 1960, quando o país se declarou independente. Os primeiros contatos foram feitos entre portugueses e o rei do Kongo, mas a exploração mais sistemática da região só começou efetivamente entre 1874 e 1878 .

Em 1878, o rei Leopoldo II, herdeiro do trono da Bélgica, negociou tratados comerciais com os chefes locais o que acarretou nos primeiros movimentos de dominação européia. No tratado de Berlim de 1885, países como França, Reino Unido, Portugal, Alemanha e Estados Unidos reconhecem a região da atual RDC como propriedade privada de Leopoldo II, na época chamada de Estado Independente do Congo (EIC). Nesses termos, o país não era uma colônia belga e sim uma propriedade do rei. As terras foram divididas em três categorias: terras indígenas, terras vacantes e terras concedidas a terceiros (MUNANGA, 2007) e colheita, exploração de minérios e produções agrícolas começaram a acontecer na região. O trabalho forçado também foi instaurado e os congoleses deveriam pagar impostos para o rei belga.

Durante o período de extração das riquezas naturais e da exploração dos nativos locais, havia métodos brutais de repressão, como chicotadas, tornar familiares reféns, fuzilamentos, mutilações e enforcamentos (MASONGELE, 2016). A exploração do marfim e da borracha é considerada a atividade econômica mais sangrenta do Estado Independente do Congo, com métodos punitivos que se assemelhavam aos praticados na escravidão. É só em 1908 que o EIC torna-se oficialmente colônia belga, mudando o nome para Congo Belga.

Nos anos 1950 começam a surgir movimentos nacionalistas africanos que exigiam a liberação da África para a criação de estados independentes (MASONGELE, 2016). Os movimentos de libertação nacional pregavam o uso da violência como instrumento contra a colonização. Cresce um grande sentimento patriótico, cada vez mais militarizado, legitimando o uso das armas no processo de independência. A União das Repúblicas Soviéticas também teve um papel de destaque nos movimentos de libertação africanos.

Em 1957 a Bélgica organizou uma eleição popular, o que fez com que o governador-geral do Congo Belga e de Ruanda-Burundi dividisse cidades e municípios. O processo, no entanto, não foi bem recebido pelos congoleses que continuaram a lutar 
Ensaio sobre a colonialidade através da história da república democrática do congo: da necropolítica à transmodernidade. Revista Ensaios, vol. 14, jan-jun de 2019.

pela independência. O ano de 1959 foi marcado por diversas manifestações e no início do ano de 1960 a Bélgica decide, junto com autoridades congolesas, a conceder a independência. A independência foi proclamada oficialmente em 30 de junho de 1960.

Mesmo com a conquista da independência, a vida dos congoleses não mudou muito, uma vez que a única força armada que existia era a força pública colonial, da qual os congoleses só podiam ocupar cargos mais baixos. Com as exigências da africanização dos quadros de comando, começaram a surgir novas revoltas dentro dos quartéis, que culminaram na efetiva africanização dos postos mais elevados e na nomeação de Joseph Mobutu como coronel chefe do Estado-maior. Mobutu planeja, então, uma conspiração contra o presidente da República, Lumumba, que é assassinado em janeiro de 1961. Mobutu conseguiu conter as revoltas populares apoiadas pelas tropas belgas, pacificando e unificando o país - processo que durou até 1965. No mesmo ano ele se autoproclamou presidente da República do Congo, "eliminando gradualmente todos os vestígios de democracia” (MASONGELE, 2016), mudando o nome do país para Zaire em 1971 e estabelecendo uma ditatura que duraria até 1997. É importante salientar que, devido ao contexto de guerra fria, a ditadura de Mobutu foi apoiada por países como França, Alemanha, Estados Unidos e até a própria Bélgica.

A partir do ano de 1977 uma forte crise econômica tomou o país, principalmente por causa do colapso dos preços do cobre internacionalmente. A população começava a dar sinais de insatisfação e de enfrentamentos ao governo, reprimindo violentamente as manifestações. Já no início da década de 1990, Mobutu começava a sofrer pressão internacional para que houvesse uma redemocratização do país, ao mesmo tempo que a situação econômica só se deteriorava (a inflação crescia em torno de 50\% por mês).

Ao mesmo tempo, a partir do ano de 1994, o país vizinho Ruanda viveu um dos maiores genocídios da história com mais de 500 mil mortes entre 7 de abril e 15 de julho deste ano. O conflito se deu porque existem duas etnias majoritárias no país, os hutus e os tutsis e, com o assassinato do presidente Juvénal Habyarimana (hutu), uma onda de violência fez com que hutus assassinassem tutsis no país. O massacre só terminou com a ascensão do novo presidente de ruanda, Paul Kagame, da etnia tutsi. Temendo uma represália, milhões de hutus fugiram para a República Democrática do Congo, mais 
Ensaio sobre a colonialidade através da história da república democrática do congo: da necropolítica à transmodernidade. Revista Ensaios, vol. 14, jan-jun de 2019.

especificamente para as regiões do leste do país: Kivu Norte e Kivu Sul. Em 1996, tropas ruandenses entram em território congolês para capturar os hutus envolvidos no massacre. As tropas começam, também, a explorar as riquezas naturais da região e, aos poucos, uma guerra civil se alastra na RDC.

Mobutu fez as manobras que pôde para continuar no poder, até que entre 1996 e 1997 ele teve que lidar com um câncer e sair momentaneamente do governo. Nesse momento surge a AFDL (Aliança das Forças Democráticas para a Liberação do Congo), liderado por Laurent-Désiré Kabila. Depois de muita pressão, Mobutu e Kabila tiveram um encontro em seu barco presidencial, mediado por Nelson Mandela, para buscar um desfecho pacífico. Mobutu foge para o Marrocos, morrendo no mesmo ano (1997) e L.D. Kabila se autoproclama presidente do Zaire, que passa a ser nomeado de República Democrática do Congo.

A entrada das tropas ruandenses na RDC faz com que muitos conflitos estourem junto com apoio internacional de países como Angola, Zimbábue e Namíbia. Em 1999 o país torna-se totalmente dividido entre forças do governo, milícias, grupos armados e guerrilheiros e entre os anos de 1998 a 2003 o período ficou conhecido como "A grande guerra do Congo". Estima-se que havia em torno de 25 grupos armados envolvidos diretamente no conflito, que se dava especialmente nas áreas norte e leste do país. Isso fez com que milhares de pessoas migrassem para a capital Kinshasa e para outras áreas menos afetadas (TANNURI, 2010).

Com o assassinato de L.D. Kabila em 2001, assume seu filho Joseph Kabila e se estabelece um acordo de paz, o Acordo de Sun City, em 2002. O acordo prevê a desmilitarização do governo, a saída de tropas estrangeiras e o desarmamento das milícias. A "grande guerra” termina em 2003, mas deixou muitas marcas no país. A migração forçada, as epidemias, a fome e a desnutrição estão entre elas. Foram 4 milhões de mortos e mais de 2 milhões de deslocamentos internos, sendo considerada a guerra mais sangrenta desde a $2^{\mathrm{a}}$ Guerra Mundial. Os conflitos, entretanto, voltaram a acontecer em 2007 e, até 2009, massacres, perseguições e ataques à população civil ainda aconteciam com alguma frequência (TANNURI, 2010). Os dados são alarmantes até 
Ensaio sobre a colonialidade através da história da república democrática do congo: da necropolítica à transmodernidade. Revista Ensaios, vol. 14, jan-jun de 2019.

hoje: são 810 mil congoleses refugiados em países africanos e 4,5 milhões de deslocamentos internos (ACNUR, 2018) ${ }^{2}$.

\section{A necropolítica em ação}

Michel Foucault estruturou o conceito de biopolítica, que se tratava essencialmente dos instrumentos de socialização modernas que exerciam duas medidas principais: a manutenção da vida de (algumas) pessoas e o extermínio de outras. Para Foucault, o Estado, unido à medicina, eram responsáveis pela potencialização da saúde humana para um bom funcionamento estatal, por isso que, num mundo capitalista, a medicina se via cada vez mais presente nos centros urbanos - porque era interessante para a própria máquina governamental que as pessoas estivessem aptas a se engajarem socialmente (FURTADO, CAMILO, 2017). O biopoder provoca a manutenção da dicotomia vida e morte enquanto parte de um exercício da soberania, mas agora acrescida de um elemento essencial: a manipulação da vida de outras pessoas, de forma que, vivas, elas possam ser mais proveitosas do que simplesmente exterminadas. Foucault ainda cita alguns exemplos extremos da soberania estatal no biopoder, como o Holocausto e o Estado de Exceção (aliado ao estado de sítio) onde o poder apela à criação de um inimigo fictício, indigno de continuar vivendo, ao mesmo tempo que uma determinada parte da população (no caso do nazismo, os alemães brancos) têm suas vidas protegidas e cuidadas. Ao dividir os seres humanos entre dignos e indignos de viver de forma biológica, Foucault rotula esse maniqueísmo de "racismo". O termo, nesse caso, é sinônimo de uma regulação de corpos vivos e mortos, tornando possível funções assassinas do Estado.

Achile Mbembe parte do conceito de biopoder em Foucault para apresentar o conceito de necropoder, insistindo que há, sim, exercício do poder na morte dos indivíduos, mas que há muitas nuances no meio do caminho. Primeiramente ele argumenta que a escravidão foi, certamente, a primeira instância de experimentação biopolítica, cuja característica essencial é a alienação de toda a humanidade de uma pessoa escravizada. Ele utiliza-se do exemplo da escravidão para explicar que é uma morte em vida.

\footnotetext{
${ }^{2}$ Fonte: https://data2.unhcr.org/en/situations/drc\#_ga=2.79017492.1634109719.1541988715735072030.1541988715, acesso em 12/11/2018
} 
Ensaio sobre a colonialidade através da história da república democrática do congo: da necropolítica à transmodernidade. Revista Ensaios, vol. 14, jan-jun de 2019.

Mbembe argumenta que o necropoder envolve não só o extermínio de indivíduos, mas as formas de subjugá-los, sabotá-los e humilhá-los continuamente. A dominação, enquanto processo sistemático de subjugação de outrem sem fornecer os meios mínimos de uma vida digna, é uma manutenção da vida que se assemelha à morte, por isso a proximidade com a escravidão. Na escravidão retira-se, ou pode-se retirar a todo momento, elementos básicos da existência humana, além das tentativas reincidentes de objetificação, degradação física e moral e submissão. Não raro, em momentos de guerras, ditaturas, prisões, eminência de tortura, etc, o suicídio é uma opção que leva à libertação: a morte enquanto libertação.

Os fatores que conceituam o necropoder são a fragmentação e divisão territorial, o acesso proibido a determinadas áreas e a aglomeração forçada de pessoas em determinados espaços pré-determinados. Esses fatores podem ser observados em diversos momentos da história mundial, em contextos de guerra, genocídio e escravidão. O necropoder também acarreta na "política da verticalidade", onde a vigilância tem um

papel essencial no controle dos corpos. A verticalização do poder também provoca hierarquias entre os oprimidos, como é o caso das milícias, guerrilhas armadas e militares na RDC. Todos, juntos, proclamam o direito ao extermínio. Existe uma dificuldade em identificar os mais de 25 grupos armados que fizeram parte da Grande Guerra do Congo, o que se dá exatamente porque o poder de metamorfose dessas organizações é gigantesco e se camufla de acordo com as demandas das diferentes situações. Às vezes estar de um lado é proveitoso, mas logo em seguida estar do outro é que o é.

\section{Colonialidade e os desafios da atualidade}

A colonialidade pode ser compreendida como o passo seguinte à colonização: na colonização, se legitima a supremacia de um povo (no caso, europeu) sobre outro, a partir de práticas de expropriação, violência e exploração. Já a colonialidade se concretiza através da burocracia e da subjetividade, como instituições e linguagens. A importância de tratarmos da colonialidade é a de entender que a modernidade só existe com ela. Os processos que se desenrolam na atualidade são fruto de uma história global que instaurou 
Ensaio sobre a colonialidade através da história da república democrática do congo: da necropolítica à transmodernidade. Revista Ensaios, vol. 14, jan-jun de 2019.

uma supremacia européia, através dos movimentos colonizadores e exploratórios de séculos passados.

A essência da colonialidade está, portanto, nessas subjetividades do dia a dia e também nas esferas políticas e econômicas onde os conceitos de "emancipação (liberal ou marxista), desenvolvimento e democracia, começa e termina com a dominação cultural, da informação e do conhecimento" (MIGNOLO, PINTO, 2015). Como já atentava Foucault, a soberania se dá pelo saber, ou seja, o conhecimento tem papel importantíssimo na manutenção da colonialidade e faz com que os autores decoloniais insistam tanto em um desligamento e desengajamento epistêmico com o ocidente.

O discurso ocidental que surgia no século XVI colocou-se como centro do mundo, apoiando-se no Renascimento e no Iluminismo e "amarrando-se" com o poder da colonização. O discurso eurocentrado é, ainda, o único discurso que é relevante, sendo todas as outras experimentações de mundo nos lugares periféricos somente sendo possíveis quando comparáveis à Europa e à sua história que é tida como a história universal. História essa que só pode ser vivida e experienciada lá - no continente Europeu - e que nas periferias (ou seja, em todo o resto do mundo, com exceção dos países norteamericanos) o tempo não é tempo do agora, porque o agora é vivido no ocidente. A tecnologia surge primeiro no ocidente, o conhecimento nasce lá, as produções mundiais estão todas lá e o que resta à periferia é um outro momento que não é o momento do agora.

\footnotetext{
Na verdade, os não europeus, "não ocidentais" são totalmente excluídos do diálogo, sequer são considerados Outros propriamente ditos; ao contrário, são dessubjetivizados, reduzidos a meros objetos de estudo, dominação e exploração. Mais: não apenas nega a participação de não europeus em sua articulação dialógica, por não considerá-los sujeitos não admitindo, por exemplo, o fato de que não haveria Europa se não existissem a América, a África e a Ásia -, o discurso europeu ocidental suprime todo e qualquer outro discurso. Ou seja, além de se apresentar como totalidade, o discurso europeu ocidental é também totalitário (MIGNOLO; PINTO, 2015)
}

Muitos dos processos mais violentos de colonização aconteceram no continente africano e, como pudemos ver na descrição da colonização da República Democrática do Congo, milhares de crimes foram cometidos contra seres humanos durante esse processo. A partilha da África foi feita de forma arbitrária, unindo diferentes etnias e causando 
Ensaio sobre a colonialidade através da história da república democrática do congo: da necropolítica à transmodernidade. Revista Ensaios, vol. 14, jan-jun de 2019.

guerras que vemos até hoje, como é o caso de Ruanda ao unir hutus e tutsis, que já tinham um histórico de conflito. Soma-se a isso uma preferência do governo belga na época, onde os tutsis tinham melhores cargos e os hutus eram marginalizados, gerando ainda mais um sentimento de injustiça e revanchismo.

A Grande Guerra do Congo é um exemplo de como a periferia, no caso, um país na África subsaariana, tem menos voz mundo colonial-moderno. Um conflito que se compara, em números, ao Holocausto, ainda tem pouca visibilidade internacional comparativa. Não há como não associar a Grande Guerra do Congo a resquícios nítidos da colonização e sintoma pulsante da colonialidade. O silenciamento desses lugares é uma nova forma de apagamento dos corpos subjugados. Se antes eles eram aniquilados, agora só são ignorados e esquecidos - características latentes do necropoder.

A colonialidade cria laços entre todo o mundo, conectados pelo centro que é a Europa. Entretanto, essa conexão mostra-se desigual, dando absoluta atenção ao Ocidente e ao que acontece nesses espaços e ignorando o que acontece no resto do mundo, ou simplesmente categorizando-o como inferior em diversos aspectos: institucionais, intelectuais e culturais. O domínio colonial europeu se deu em todas as regiões do planeta incorporando-as a um "sistema-mundo", que serve de sustento para a soberania ocidental (QUIJANO, 2005) É nesses termos que apresentamos o termo da colonialidade ligada, necessariamente, à modernidade. Uma não existe sem a outra e só conseguimos compreender a modernidade levando em consideração um processo colonizador que perdura até hoje. É a fundição das "experiências do colonialismo e da colonialidade com as necessidades do capitalismo" que se dá a modernidade (QUIJANO, 2009). E Mignolo e Pinto completam a análise afirmando que existe uma dupla face da modernidade, na qual há "de um lado, a retórica da salvação e bem-aventurança por meio do progresso e do desenvolvimento e, de outro, [...] a violência, a exploração e a expropriação necessárias à realização da promessa de salvação” (2015).

\section{A imposição epistemológica ocidental}


Ensaio sobre a colonialidade através da história da república democrática do congo: da necropolítica à transmodernidade. Revista Ensaios, vol. 14, jan-jun de 2019.

Os impactos materiais da colonialidade podem ser percebidos com clareza nos conflitos modernos em países que eram antes colônias. Mas como se dá a subjetividade do poder que tem tanta força e consegue produzir diferenças tão gritantes?

Para Boaventura de Souza Santos, existe um limiar bastante demarcado no que ele chama de pensamento abissal. Abissal porque existe um "abismo" entre a articulação do conhecimento hegemônico e o conhecimento popular, leigo, indígena ou camponês - que é sempre desqualificado pela primeira forma de conhecimento. O monopólio do conhecimento se dá através de duas áreas: a ciência, de um lado, e a teologia e a filosofia, do outro. "[A visibilidade desses conhecimentos] assenta na invisibilidade de formas de conhecimento que não se encaixam em nenhuma dessas modalidades" (SANTOS, 2007). Esses lugares, portanto, não produzem conhecimento, e sim crenças, opiniões, magia interessantes apenas como objetos de estudo da episteme hegemônica.

Para Ramon Grosfoguel é no pensando de René Descartes que se inaugura a egopolítica do conhecimento, antropocentrista. O pensamento autocentrado de "penso, logo existo", aos olhos de Enrique Dussel (1994), nasce na existência do colonizador, que se intitulava um ser superior. Essa semente deu lugar à modernidade eurocentrada e de sujeitos que acreditavam ter acesso a uma verdade universal (GROSFOGUEL, 2007).

Os contratualistas - Locke, Hobbes, Rousseau - já falavam que era através de um contrato social que os seres humanos saíam de um estado de natureza para se organizarem em sociedade. O encontro com os povos nativos nas Américas e na África só reiteraram que o que se passava no ocidente, especialmente relativo às leis e a organização do Estado, não se aplicava no Novo Mundo. Ao ser posta em dúvida a presença de alma nesses sujeitos e aproximando-os da natureza, tudo o que deveria ser seguido no ocidente, como as leis e as regras, não cabiam mais naquele lugar, dando espaço para a expropriação e a violência.

A profunda dualidade do pensamento abissal e a incomensurabilidade entre os termos da dualidade foram implementadas por meio das poderosas bases institucionais - universidades, centros de pesquisa, escolas de direito e profissões jurídicas - e das sofisticadas linguagens técnicas da ciência e da jurisprudência. O outro lado da linha abissal é um universo que se estende para além da legalidade e da ilegalidade e para além do verdade e da falsidade. Juntas, essas formas de negação radical produzem uma ausência radical: a ausência de humanidade, a subumanidade moderna. Assim, a exclusão se torna simultaneamente 
Ensaio sobre a colonialidade através da história da república democrática do congo: da necropolítica à transmodernidade. Revista Ensaios, vol. 14, jan-jun de 2019.

radical e inexistente, uma vez que seres subumanos não são considerados sequer candidatos à inclusão social. [...] A negação de uma parte da humanidade é sacrificial, na medida em que constitui a condição para que a outra parte da humanidade se afirme como universal (SANTOS, 2017).

A importância desse conceito apresentado por Boaventura Santos é de percepção da subumanidade persistente até hoje, perpetuada através de outros artifícios. A invisibilidade da Grande Guerra do Congo, a indiferença aos surtos de ebola e aids em países africanos e o desdém à luta dos povos originários nas Américas são sinais da colonialidade e da discrepância que existe entre os dois lados mundiais: "centro" e "periferia".

A modernidade nos demonstrou, entretanto, que uma resistência vem sido feita pelos indivíduos dessas "periferias" através da migração. Para Santos, o que se põe em prática nesse momento é o regresso do colonial, que pode se assumir de três formas: na do terrorista, do imigrante indocumentado e do refugiado. Cada uma dessas formas é contida de formas diferentes, mas basicamente se utilizando de burocracias e legislações próprias. O indivíduo colonial (advindo de ex-colônias) agora pode chegar às metrópoles, o que antes só poderia ser feito através do colonizador (como a entrada de escravos nos centros urbanos). A reação é a remarcação da linha abissal, na tentativa de reiterar o local de supremacia hegemônica e de subalternidade.

E aqui voltamos aos princípios do necropoder: para conter esses processos migratórios, novas políticas "anti-terrorismo" são aplicadas, escalando um estado de ascensão que retira direitos democráticos adquiridos sob o pretexto de salvaguarda de determinados indivíduos. As novas linhas abissais materiais são os campos de refugiados e os muros erguidos na Cisjordânia; já as linhas subjetivas se traduzem em novas legislações e burocracias que impedem a entrada de pessoas não desejáveis nesses territórios.

\section{A transmodernidade e o giro decolonial}

A decolonialidade é um termo utilizado de forma crítica às matrizes de poder colonial, visando pensar a modernidade desatrelada da hegemonia ocidental e ao histórico 
Ensaio sobre a colonialidade através da história da república democrática do congo: da necropolítica à transmodernidade. Revista Ensaios, vol. 14, jan-jun de 2019.

de colonização da atualidade. Aimé Césaire criticou o pensamento universalista europeu, especificamente o pensamento marxista eurocêntrico, afirmando que há novas possibilidades de pensar o "universal" em termos de coexistência de diferentes indivíduos e sociedades (CÉSAIRE, 1978).

A produção de conhecimento e poder universalista que Césaire critica se reproduz nos espaços não ocidentais, negando particularidades de formas de cultura e organização de povos originários dos diferentes continentes. Se o poder hegemônico ocidental se dá de forma vertical, Césaire propõe uma forma que seja horizontalizada entre todas as sociedades, considerando as particularidades de cada uma. Pensar essa horizontalidade advém de um pensamento também universalista, mas que não seja embasado em conceitos de uma cosmologia e epistemologia ocidental. Um pluri-verso ao invés de universo.

Grosfoguel argumenta que "a liberação só pode advir de pensadores críticos de cada cultura em diálogo com outras culturas" (GROSFOGUEL, 2007), de forma que o ocidente não possa impor sua organização a outras sociedades e sim que haja trocas a fim de encontrar soluções para uma política global - e, portanto, pluri-versalista. A democracia liberal ocidental se impõe mundialmente e, quando não aceita por determinados países ou localidades, institui-se através da força em nome de um progresso civilizatório. Os exemplos que temos disto na atualidade são a guerra no Iraque e o apoio dos EUA à Arábia Saudita, a fim de controlar territórios que reagem à forma imperialista do país norte americano.

E qual, afinal, as características de uma transmodernidade? É importante salientar que transmodernidade não é o mesmo que pós-modernidade, esse segundo termo sendo uma crítica eurocêntrica ao eurocentrismo (GROSFOGUEL, 2007). A transmodernidade é uma forma de pensar os processos globais através das particularidades de diferentes grupos sociais, atreladas a uma malha que se cruza, universal - ou pluri-versal, onde todas as pequenas demandas tornam-se negociáveis e relevantes, independentemente da sua localidade (de ser numa "periferia" ou no "centro").

O giro decolonial, portanto, apresenta uma nova forma de colocar as demandas que não se encontram nesse "centro", mudando o foco da episteme global e dando espaço para 
Ensaio sobre a colonialidade através da história da república democrática do congo: da necropolítica à transmodernidade. Revista Ensaios, vol. 14, jan-jun de 2019.

a ciência produzida nos países dominados. Em 2005, o filósofo porto-riquenho Nelson Maldonado-Torres cunhou o termo "giro decolonial" (BALLESTRIN, 2013) que significava o movimento de resistência teórico e prático, político e epistemológico, à lógica da modernidade/colonialidade, aquela que compatibilizou o progresso de poucos com graus indescritíveis de violência e miséria (MIGLIEVICH-RIBEIRO, 2017).

\section{Conclusão}

A colonização da República Democrática do Congo e todo seu processo de modernização ilustram bem o conceito de necropoder em Mbembe. O exemplo da RDC é só um dos vários que poderia ter sido abordado nesse artigo, porque as histórias se repetiram com frequência durante o processo de colonização mundial.

A contribuição de Mbembe é relevante porque consegue ir além de uma dicotomia vida e morte, atentando à humilhação e à sabotagem que os países dominadores exercem nos países dominados. A apatia e a indiferença também são aspectos desse "deixar morrer": num mundo de conexões globais instantâneas, ocultar eventos como a Grande Guerra do Congo - que mais matou civis depois da Segunda Guerra Mundial - é pactuar com um apagamento da história negra africana.

Ao se deparar com indivíduos negros, os brancos os categorizavam não enquanto humanos, mas sim selvagens - parte da natureza. Toda a organização européia, a racionalização européia, não valia de nada nas colônias do sul, uma vez que os Estados das colônias não têm validade por não serem iguais aos Estados europeus; seus soberanos não são soberanos reconhecidos no ocidente; e não se estabelecem diferenciações militares entre "aliados" e "inimigos". As colônias não são nada além de balbúrdia e desordem, onde tudo pode "do lado debaixo do equador", onde não há fisscalização e onde as regras ocidentais não valem de nada. 
Ensaio sobre a colonialidade através da história da república democrática do congo: da necropolítica à transmodernidade. Revista Ensaios, vol. 14, jan-jun de 2019.

Da negação racial de qualquer vínculo comum entre o conquistador e o nativo provém a constatação de que as colônias possam ser governadas na ilegalidade absoluta. Aos olhos do conquistador, "vida selvagem" é apenas outra forma de "vida animal", uma experiência assustadora, algo alienígena além da imaginação ou compreensão (MBEMBE, 2018).

Existe uma importância latente na subjetividade que perdura a manutenção do poder desses "centros" nas "periferias". Não bastassem anos de colonização e violência física, na modernidade percebemos que esses fatores continuam articulados de forma simbólica, principalmente através de burocracias, leis e controles econômicos e epistêmicos. O papel da colonialidade é o de perpetuação da hegemonia ocidental através de novos artifícios que mantém as premissas da colonização. Existe, para tal, um monopólio do conhecimento nascido e mantido pelo ocidente que deslegitima o conhecimento de povos originários, relegando-os aos rótulos de crença, magia e opinião - sem valor para as metrópoles.

A resistência da periferia se enxerga de forma cada vez mais latente: imigrações em massa, caravanas tentando adentrar países norte-americanos, resistência e organização popular, revoltas civis e fugas ilegais. E a resposta segue reafirmando as linhas abissais, ferindo direitos humanos de alguns para privilegiar a existência de outros. Os conflitos, entretanto, não parecem próximos de um fim, exigindo que pensemos efetivamente em como curar marcas de um passado de colonização traduzido em uma política colonial que subjuga corpos e tenta reter a reação.

Novas perspectivas surgem no campo do conhecimento ao mesmo que tempo que vemos o que está se pondo em prática no mundo material. Os conceitos de transmodernidade e o giro colonial certamente nos abrem portas para uma descentralização política, econômica e epistemológica, dando margem para que os saberes advindos das não-metrópoles tenham força na revisão do pensamento hegemônico entranhado na atualidade. A horizontalização do saber-político é uma das chaves para problematizar a construção verticalizada e impositiva que se aparece como falida na conjuntura atual. Os autores que aqui citei deram algumas dicas de como fazer essa descentralização, mas só com erros e acertos encontraremos um ponto comum na resolução dos dilemas da modernidade. 
Ensaio sobre a colonialidade através da história da república democrática do congo: da necropolítica à transmodernidade. Revista Ensaios, vol. 14, jan-jun de 2019.

\section{Referências:}

BALLESTRIN, Luciana. América latina e o giro decolonial. Revista Brasileira de Ciência Política, nº11. Brasília, maio - agosto, 2013, p. 89-117.

CÉSAIRE, Aimé. Discurso sobre el colonialismo. Livraria Sá da Costa Editora, 1978.

FURTADO, R. N.; CAMILO, J. A. O. O conceito de biopoder no pensamento de Michel Foucault. Subjetividades, v. 16, p. 34-44, 2017.

GROSFOGUEL, Ramón. Descolonizando los universalismos occidentales: el pluriversalismo transmoderno decolonial desde Aimé Césaire hasta los zapatistas. In: CastroGómez, Santiago \& Grosfoguel, Ramon (coords.) El giro decolonial: reflexiones para uma diversidad epistêmica más allá del capitalismo global. Bogotá: Siglo del Hombre Editores, Universidad Central, Instituto de Estudios Sociales Contemporáneos, Pontificia Universidad Javeriana, Instituto Pensa, 2007.

MASONGELE, Genick Mbaki. Imperialismo: Do mundo para a colonização do Congo. Dissertação (Mestrado em Desenvolvimento Regional) - Fundação Universidade Federal do Tocantins, Palmas, 2016.

MBEMBE, Achille. Necropolítica. n-1 edições, 2018.

MIGLIEVICH-RIBEIRO, Adelia Maria. O giro decolonial latino-americano: um movimento em curso. Rio de Janeiro: IESP-UERJ, 2017 (Blog do Sociofilo: (Co)Laboratório de Teoria Social - Iesp-Uerj).

MIGNOLO, Walter; PINTO, Júlio Roberto de Souza. A modernidade é de fato universal? Reemergência, desocidentalização e opção decolonial. Civitas, v. 15, nº 3, jul. set. 2015.

QUIJANO, Anibal. Colonialidade do poder e classificação social. In: Santos, Boaventura de Souza \& amp; Meneses, Maria Paula. Epistemologias do Sul. Coimbra, Edições Almendina, 2009.

Colonialidade do poder, eurocentrismo e América Latina. In: Lander, Edgardo (org). Colonialidade do saber: eurocentrismo e ciências sociais. Buenos Aires: CLACSO, 2005.

SANTOS, Boaventura de Sousa. Para além do pensamento abissal. Revista Novos Estudos, CEBRAP, nº 79, p. 71-94, 2007.

TANNURI, Maria Regina P. Refugiados Congoleses no Rio de Janeiro e Dinâmicas de "Integração Local": das ações institucionais e políticas públicas aos recursos relacionais das redes sociais. Tese (Doutorado em Planejamento Urbano e Regional) - Universidade Federal do Rio de Janeiro. 2 v. Rio de Janeiro, 2010. 